\title{
Technology of Manufacturing of Disk Blanks to High-Speed Elements for Tests on Anti- Meteoroid Protection
}

\author{
Pavel V. Kruglov ${ }^{1 *}$ and Irina A. Bolotina ${ }^{1}$ \\ ${ }^{1}$ Bauman Moscow State Technical University, 2nd Baumanskaya str., 5/1, 105005, Moscow, Russia
}

\begin{abstract}
In this paper, a variant of the manufacturing technology of the disk blank for the segment liner of the shape charge is proposed. The charges are used to test the anti-meteorite stability of spacecraft. The proposed method makes it possible to form a blank in which, as its thickness decreases from the center to the periphery, a periodic profile variable in thickness is formed simultaneously in the circumferential direction. The disk metal blank is fixed in a three-cam chuck and the end face of the disk is cut with a decrease in thickness along the generatrix from the center to the periphery. Under the action of fastening forces, the disk blank is deformed and after processing the thickness in the cross section has a triangular periodic profile. Experiments on processing of disk preparations at various efforts of machine device are carried out. The dependences of the disc thickness on the fastening force in the device are obtained. After harmonic analysis of the thickness of the cross section, the values of the amplitudes of harmonics of different thickness in the circumferential direction at different distances from the center of the disk blank were determined. An increase in the fastening force leads to an increase in the amplitude of the third harmonic of the part thickness. It is shown that the change in the amplitudes of the first and second harmonics of different thickness is insignificant, and the amplitude of the third harmonic increases from the center to the periphery, which is caused by a decrease in the stiffness of the workpiece in the peripheral region.
\end{abstract}

\section{Introduction}

It is known that shape charges are used for tests on the anti-meteorite stability of spacecraft [1-5]. The action of such a shape charge is based on the interaction of a high-speed compact element, which is a metal liner thrown by an explosive, with an barrier. In the design of the charge, such a liner has a conical or segmental shape, is made of steel, copper, tantalum and other material [1-8]. In this paper, charges with segmental steel liner are considered [6-8].

After initiating the explosive, the liner is crimped and takes the form of an elongated high-speed element. To stabilize its flight, it is recommended to form an aerodynamic skirt in the tail region, which has a periodic, multi-vertex cross-section profile variable in

* Corresponding author: kpv17@bmstu.ru 
thickness. The creation of such an element profile is possible in various ways, using modifications of both the liners [2-9] and the explosive charge [10-11]. In works [11-14] it is proposed to use overlays on metal cladding, multipoint initiation to increase the efficiency of such charges. The process of penetration of such elements into the barrier is studied experimentally [15-18]. Mathematical modeling is used to reduce research costs [68, 19-25]. As the results of studies [6-8] show, the shape of the segmental metal liner has the greatest influence on the parameters of the high-speed element, so in this work the main attention is paid to this part of the charge.

Studies show [9] that when modifying the liner, the height of such vertices along its thickness in the circumferential direction should be small, and in the periphery of the liner, the height should not exceed less than millimeter. In work [9] it is offered to receive the specified profile by methods of sputtering or surfacing that is rather laborious and does not guarantee achievement of the specified accuracy. Manufacturer of wall with periodic thickness variation requires improvement to achieve the specified accuracy.

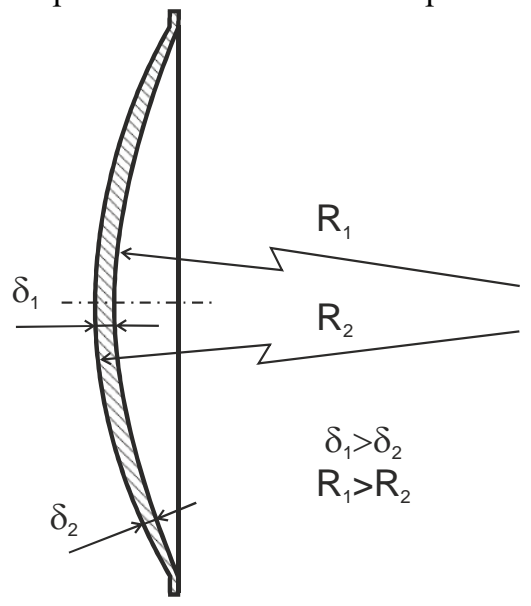

Fig. 1. Segmental liner of the shaped charge.

In this paper, a variant of the manufacturing technology of the disk blank for the segment liner of the shape charge is proposed (Fig.1), allowing to form such a blank, in which a decrease in the thickness of the blank from the center to the periphery simultaneously in the circumferential direction, a variable thickness periodic profile is formed.

\section{Materials and Methods}

For production of such liner it is offered to use the technological process including operations of reception of disk preparation (stamping or a segment from a circle), mechanical processing of disk preparation, stamping-forming in an elastic matrix for giving of a segmental form of a detail. The required part cross-sectional profile in the radial and circumferential directions (thickness reduction from the center to the periphery and periodic fluctuations in the circumferential thickness) will be formed in the machining operation, and then will be inherited by the part after stamping.

The technological operation of machining is performed on a lathe when fixed in a threecam chuck. As a blank, a disk blank obtained by cutting in a die or by cutting from a circle of the corresponding diameter is used. When fixing a thin-walled disk blank in a three-cam chuck, it is deformed under the action of fastening forces and when turning the end surface, the thickness of the workpiece in the circumferential direction will be variable. Trimming 
of the end is performed by the undercut cutter in one or more passes from the center to the periphery with a gradual increase in the depth of cut. The resulting end surface will not be flat, but conical, since the thickness of the segment facing in the center of the part (in the dome) should be greater than in the periphery. For liners up to $100 \mathrm{~mm}$ in diameter, the thickness in the peripheral area does not exceed $1 . .3 \mathrm{~mm}$. The problems with machining according to this scheme are the reliable fastening of the workpiece in the three-cam chuck, since the width of the fastening $(1 . .3 \mathrm{~mm})$ small and high probability to touch the cutter cams when processing the peripheral area (Fig.2).

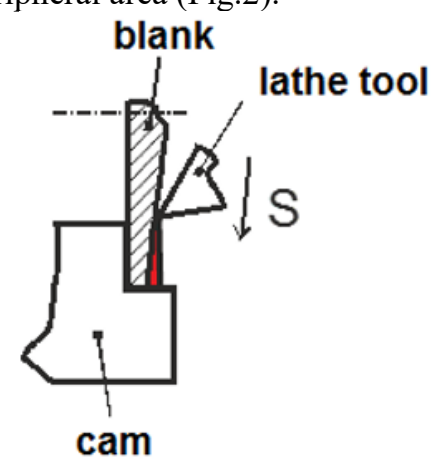

Fig. 2. Trimming the end of the disc when fixed in a three-cam chuck (filling marked a dangerous area during processing).

To solve this problem, it is proposed to choose a disk blank of obviously larger diameter (about 10-25\%), and form a conical surface when trimming the end with the abandonment of the technological shoulder, which will act as a base and will not be worn off in the process of trimming the end (Fig.3). The width of the shoulder for reliable fastening depends on the material to be processed, the thickness of the workpiece, the diameter and is selected empirically.

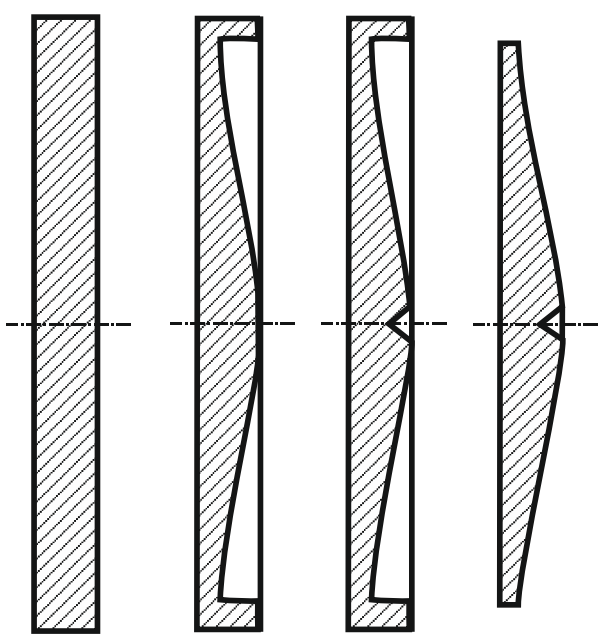

Fig. 3. Cross-section of the workpiece at different processing operation.

For the subsequent removal of the technological shoulder on the surface of the workpiece is formed a center hole, the workpiece is reinstalled in the centers and the shoulder through the cutter is ground in several passes (Fig.4). 


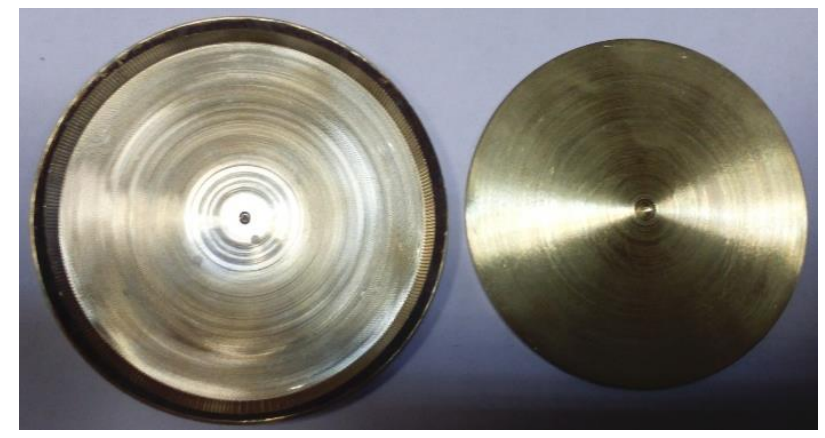

Fig. 4. Blank with a shoulder (left) and after processing without a shoulder (right).

To test the technology, experiments were carried out to obtain disc parts with a diameter of $68 \mathrm{~mm}$, a thickness in the center $2 . .2 .5 \mathrm{~mm}$, on the periphery $1.5 .2 .1 \mathrm{~mm}$. as the initial disk blanks were used circles with a diameter of $75 \mathrm{~mm}$, a thickness of $4 \mathrm{~mm}$, made of brass L63. Brass has close to copper technological properties and lower cost, which determined the choice of material for the experiment. Processing was carried out on a lathe 1A62. The workpiece was mounted in a three-cam chuck, fastening was performed with a torque wrench with a fixed torque on the key while the fastening force was recorded in each experiment.

Values of the moment on a key at fastening were accepted equal $25 ; 40 ; 55 ; 70 ; 85 \mathrm{~N} \bullet \mathrm{m}$ which further were recalculated in efforts of fastening. During processing, the depth of cut increased from $1.5 \mathrm{~mm}$ in the center to $2.5 \mathrm{~mm}$ on the periphery of the disc. Spindle speed $\mathrm{n}=240 \mathrm{rpm}$, cross feed $\mathrm{s}=0.125 \mathrm{~mm} / \mathrm{rpm}$. The width of the technological shoulder was 3.5 mm per side (Fig. 4).

\section{Results}

After processing, to evaluate the results of the experiments, thickness measurements were performed in the circumferential direction at a radius of $32 \mathrm{~mm}$ (at a workpiece radius of 34 $\mathrm{mm}$ ) through 15 degrees at 24 points, one of the workpieces was measured in the circumferential direction at a radius of $27 \mathrm{~mm}$ (Fig.5).

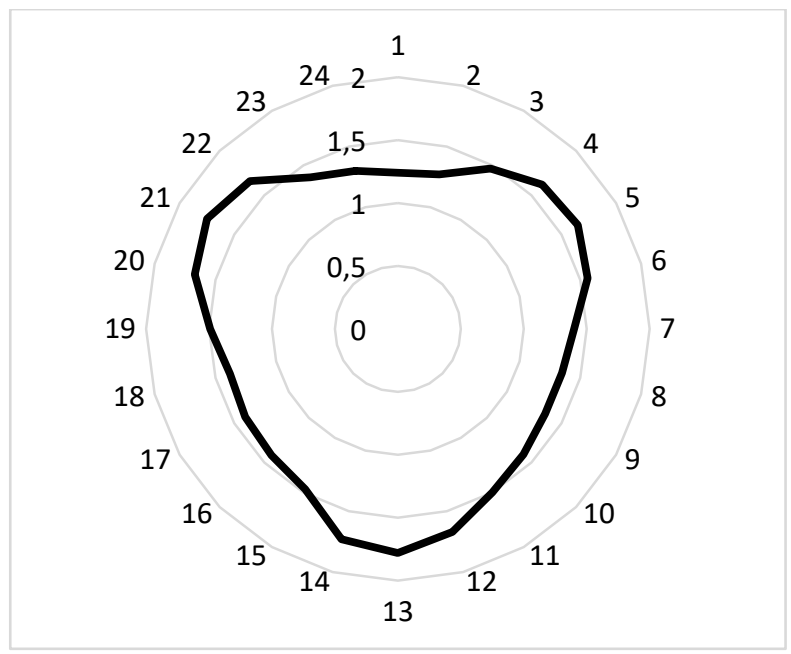

Fig. 5. The thickness $\delta$ in mm of the workpiece at a radius of $32 \mathrm{~mm}$. 
Measurements were carried out at marked points of the workpiece on the Abbe comparator with a division value of 1 micron. The results were entered in a table and then processed in Excel. The thickness in the circumferential direction was determined by the results of measurements (Fig. 5) and the thickness difference, as the difference between the current thickness value and the minimum value in a given direction.

Harmonic analysis was used to study the cross-sectional profile in the circumferential direction. According to the method of using this approach in relation to the analysis of the geometry of shape charges, the study of thickness and thickness in the circumferential direction was carried out. When describing the periodic function using the Fourier series, it is possible to identify the largest amplitudes of harmonics and explain the reasons for their appearance. Harmonic analysis was used to reduce errors in the cross-section of conical shaped liners. In this paper, it is proposed to identify one of the higher harmonics, in particular, the third, by means of harmonic analysis, to control and control its value at different operations of liner manufacturing.

The results of the harmonic analysis of the values of the liner thickness in the circumferential direction at a radius of $32 \mathrm{~mm}$ from the center are presented in Figure 6.

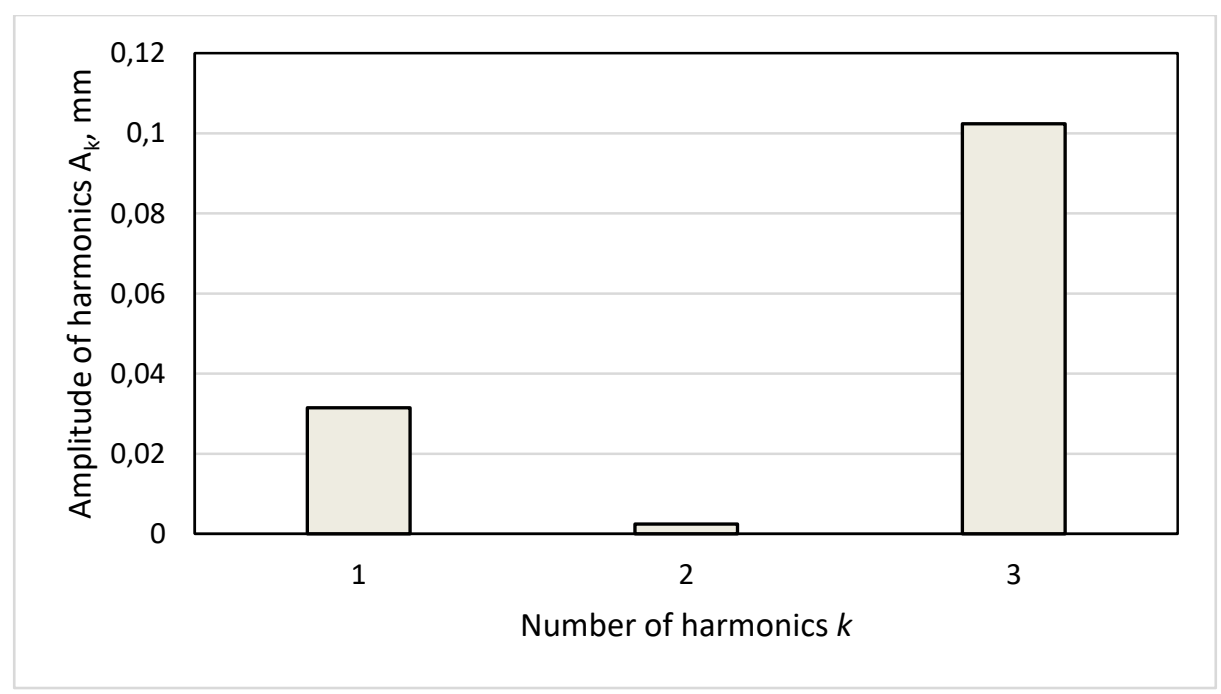

Fig. 6. The amplitude of harmonics of the thickness variation of the workpiece after harmonic analysis.

As can be seen, the amplitude of the third harmonic has the highest value among the first three harmonics and exceeds the amplitude of the first harmonic by 3.2 times, and the second by more than an order of magnitude. This shows that the proposed method of machining forms a workpiece with the necessary periodic error structure-thickness difference, which will create a three-vertex thickness profile in the circumferential direction.

The next step is to study the effect of the fastening force on the size of the thickness. The results are shown in Figure 7. 


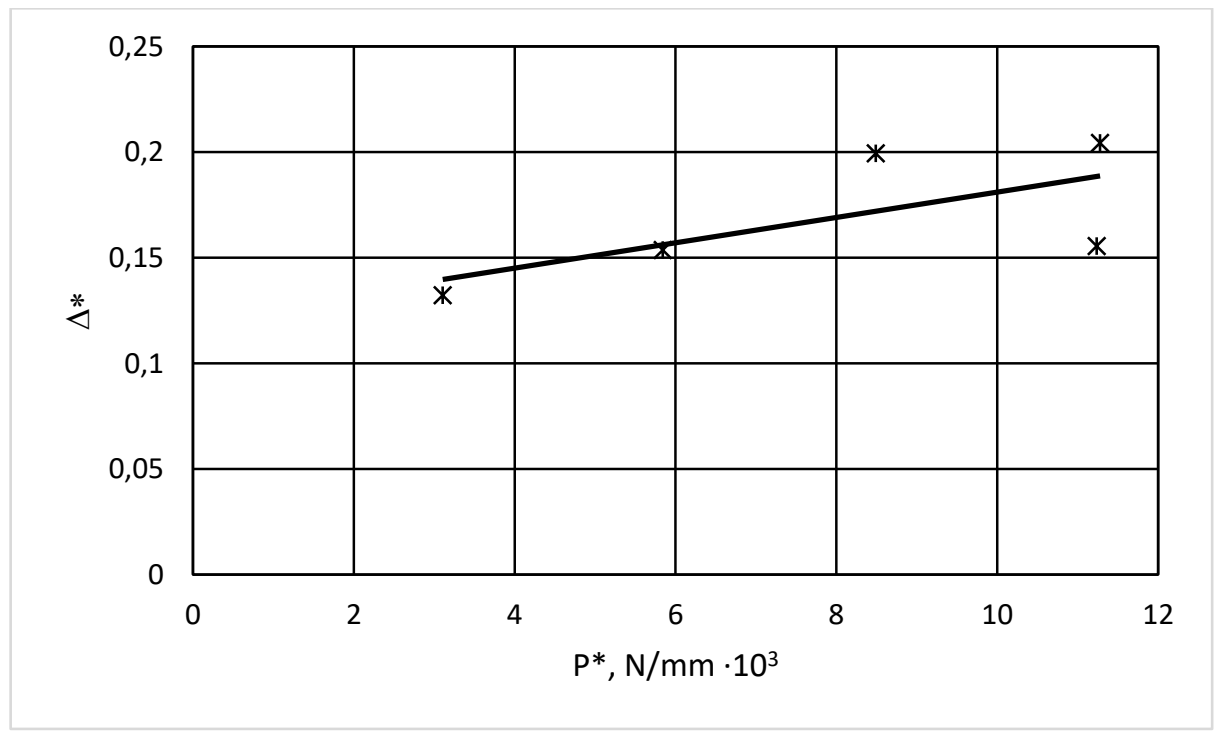

Fig. 7. Dependence of the relative thickness $\Delta *$ of the workpiece at a radius of $32 \mathrm{~mm}$ on the value $\mathrm{P}^{*}$.

The experimental results allow us to construct a linear dependence

$$
\Delta^{*}=0,006 P^{*}+0,1211
$$

where $\Delta^{*}=\frac{\Delta}{\delta}$ - is the ratio of thickness $\Delta$ to the thickness of the part $\delta$,

$\mathrm{P}^{*}=\frac{\mathrm{P}}{\delta}$ - the ratio of the fastening force $\mathrm{P}$ to the thickness of the part $\delta$.

With an increase in the fastening force, the value of the thickness increases, which can be explained by an increase in the deformation of the workpiece in the transverse direction. It should be noted that additional experiments are needed to clarify this dependence for a larger range of thicknesses and different materials.

For one of the details, a harmonic analysis of the thickness difference in the circumferential direction at different distances from the center of 27 and $32 \mathrm{~mm}$ was carried out (Fig.8). As the results of the analysis showed, the values of the amplitudes of the first and second harmonics increase slightly, and the values of the amplitudes of the third harmonic at a distance of 27 and $32 \mathrm{~mm}$ from the center differ by more than 4 times. The amplitudes of the first and second harmonic to grow with increasing distance from the center, due to the fact that the first harmonic describes the displacement of the billet center relative to the center of the dimension in the radial direction under the same conditions of measurement it is equally small, and second harmonic component characterizes the curved workpiece along one of the diametrical lines, and is likely to be associated with the characteristics of the rolled sheet, which was made blank. Such a slight increase in the second harmonic in the experiment correlates with a proportional increase in the thickness of the workpiece from the center to the periphery when obtaining a conical surface in the conditions of" curvature " of the workpiece. Of greater interest is a significant change in the amplitude of the third harmonic. It can be assumed that this difference (more than 4 times) caused a significant deviation of the workpiece during the machining in the axial direction under the action of cutting forces, since the workpiece is reduced in the peripheral regions 
due to firstly, increase the distance from the attaching points, and, secondly, because reducing the thickness of the workpiece from the center to the periphery. A further way to reduce the amplitude of the third harmonic will be to find ways to reduce the cutting force in the process of trimming the end face.

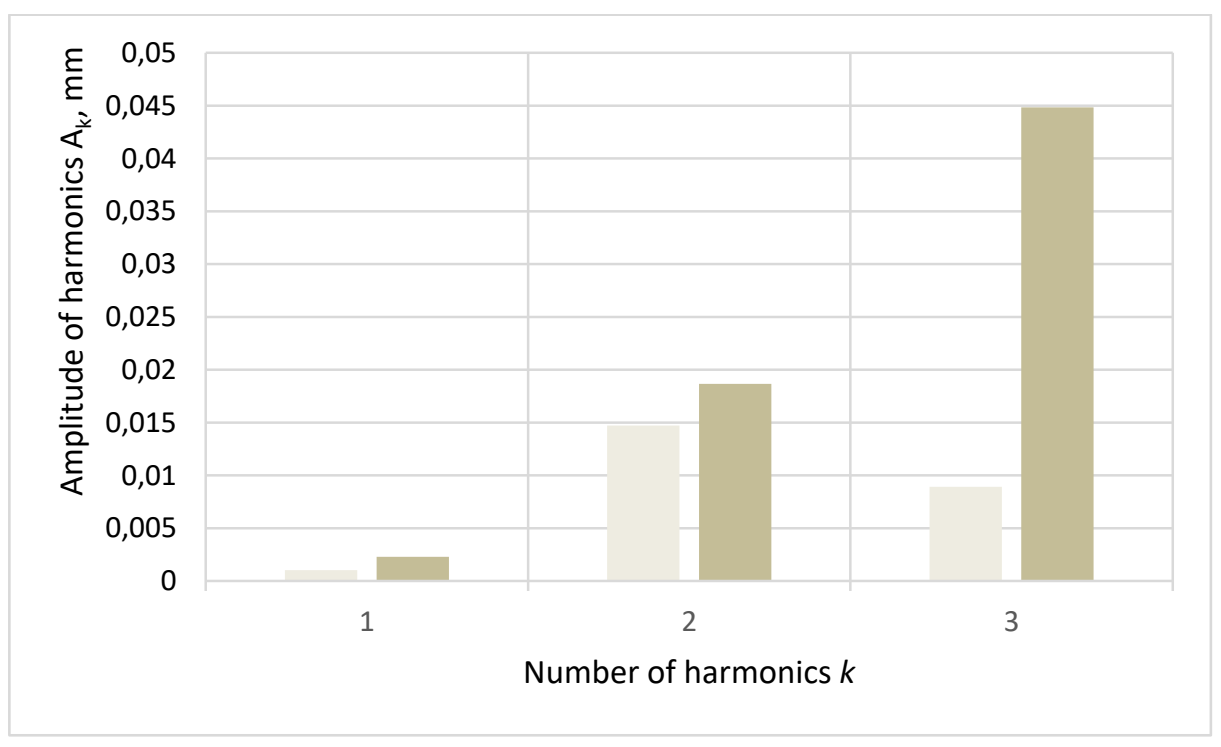

Fig. 8. Amplitudes of harmonics of the part thickness in the circumferential direction at a distance of 27 (light) and 32 (dark) $\mathrm{mm}$ from the center.

The next operation of the technological process of manufacturing of liner offers stamping disc blanks in an elastic matrix, as it would involve giving the necessary form details the conditions of preservation without changing the thickness of the workpiece and of the inheritance of part of variable thickness formed on the machining stage.

\section{Discussion and application in the education}

The considered technique is developed and used in educational process of chair of technologies of rocket and space mechanical engineering at studying of technological equipment of process of tests of rocket and space equipment. Calculations are performed and processed using standard techniques in MS Excel and MathLab. Students determine the required geometric parameters of the workpiece in the process of fixing, select the fixing force and register the values of deformations. According to the results of the experiments build graphs, the relationship between the fastening force and deformation of the workpiece and prepare a report.

\section{Conclusion}

Thus, the paper shows that in the manufacture of metal disk blanks by machining it is possible to form a periodic thickness profile in the cross section of the workpiece while reducing the thickness of the disk from the center to the periphery. To do this, it is proposed to use a larger diameter workpiece with a technological shoulder, which serves as a base for processing and is later removed. The presence of such a technological shoulder allows you 
to fix the workpiece when processing the end without the risk of damage to the processing device.

After harmonic analysis of the thickness of the cross-section in the circumferential direction, the thickness dependences on the fastening force in the device are obtained. An increase in the fastening force leads to an increase in the amplitude of the third harmonic of the part thickness. The values of harmonics amplitudes of different thickness in the circumferential direction at different distances from the center of the disk blank are determined. It is shown that the change in the amplitudes of the first and second harmonics of different thickness is insignificant, and the amplitude of the third harmonic increases from the center to the periphery, which is caused by a decrease in the stiffness of the workpiece in the peripheral region.

This method used for studying in Bauman Moscow State Technical University for students on aerospace manufacturing.

\section{References}

1. W.P. Walters, J.A. Zukas, Fundamentals of Shaped Charges. N.Y., John Wiley and Sons, p. 298 (1989)

2. V.V. Selivanov, S.V. Fedorov, Ya.M. Nikolskaya, S.V. Ladov, Compact element formation for the modeling of the high-velocity impacts of particles onto spacecraft materials and construction elements in earth conditions, Acta Austronautica, vol. 135, pp. 34-43 (2017)

3. V.V. Selivanov, S.V. Fedorov, Ya.M. Nikolskaya, S.V. Ladov, Research of the explosive formation of a compact element for meteoroids fragments and space debris modelling, Acta Austronautica, vol. 163, pp. 84-90 (2019)

4. S.V. Fedorov, V.V. Selivanov, V.A. Veldanov, Calculation analysis of magnetic-pulse compaction of explosively formed high-velocity metal elements used for meteoroid protection testing, Acta Astronautica, Vol. 135, pp. 44 - 55 (2017). DOI: 10.1016/j.actaastro.2016.10.024

5. S.V. Fedorov, S.V. Ladov, Ya.M. Nikolskaya, Computational and experimental research of explosive meteorial devices with combined cumulative liners of the semisphere-cylinder shape, Journal of Physics: Conference Series, Vol. 894, No 1 .- Art.no 012066 (2017). DOI: 10.1088/1742-6596/894/1/012066

6. P.V. Kruglov, V.I. Kolpakov, Mechanism of explosive formation of high-velocity elongated projectiles from steel segment lining, Engineering Journal: Science and Innovation, 12 (2017). http://dx.doi.org/10.18698/2308-6033-2017-12-1714.

7. P.V. Kruglov, V.I. Kolpakov, Analysis of influence of metal linings profile heterogeneity on the high-speed elongated elements shape, Engineering Journal: Science and Innovation, 7 (2018). http://dx.doi.org/10.18698/2308-6033-2018-7-1782.

8. V.I. Kolpakov, I.A. Bolotina, P.V. Kruglov, Simulation of the design process of the high-speed elongated aircrafts with variable form, AIP Conference Proceedings 2171, 030016 (2019). DOI://doi.org/10.1063/1.5133182.

9. N.A. Asmolovskiy, V.D. Baskakov, V.A. Tarasov, The impact of periodic disturbances on the formation of high-speed rod elements, Izvestia vuzov. Mashinostroenie, № 8, p. 8-14 (2013)

10. K. Weimann, Research and development in the area of explosively formed projectiles charge technology, Propellants, explosives, pyrotechnics, vol. 18, iss. 5, pp. 294-298 (1993) 
11. J. Liu, W. Gu, M. Lu, H. Xu, S. Wu, Formation of explosively formed penetrator with fins and its flight characteristics, Defense Technology, № 10, p.119-123 (2014). doi:10.1016/j.dt.2014.05.002.

12. D. Bender, B. Chhouk, R. Fong, B. Rice, E. Volkmann, Explosively formed penetrators (EFP) with canted fins, 19th International Symposium on Ballistics, Interlaken, Switzerland, 7-11 May 2001, Defence Science and Technology Organization, the International Ballistics Committee, Interlaken, DEStech Publications, pp. 755-761 (2001)

13. W. Li, X. Wang, W. Li, The effect of annular multi-point initiation on the formation and penetration of an explosively formed penetrator, International Journal of Impact Engineering, vol. 37, iss. 4, pp. 414-424 (2010)

14. R. Li, W.B. Li, X.M. Wang, Effects of control parameters of three-point initiation on the formation of an explosively formed projectile with fins, Shock Waves, vol. 28, iss. 2, pp. 191-204 (2018)

15. S. Pappu, L.E. Murr, Shock deformation twinning in an iron explosively formed projectile, Materials Science and Engineering, vol. 284, iss. 1-2, pp. 148-157 (2000)

16. S. Pappu, L.E. Murr, Hydrocode and microstructural analysis of explosively formed penetrators, Journal of materials science, vol. 37, iss. 2, pp. 233-248 (2002)

17. F. $\mathrm{Hu}, \mathrm{H}$. Wu, Q. Fang, J. C. Liu, Impact resistance of concrete targets pre-damaged by explosively formed projectile (EFP) against rigid projectile, International Journal of Impact Engineering, vol. 122, pp. 251-264 (2018)

18. F. Hu, H. Wu, Q. Fang, J. C. Liu, B. Liang, X. Z. Kong, Impact performance of explosively formed projectile (EFP) into concrete targets, International Journal of Impact Engineering, vol. 109, pp. 150-166 (2017)

19. V.V. Selivanov, Numerical simulation and experimental study of explosive projectile devices / V.V. Selivanov, E.F. Gryaznov, N.A. Goldenko, A.D. Sudomoev, V.A. Feldstein, Acta Astronautica, Vol. 135, pp. 56 - 62 (2017). DOI: 10.1016/j.actaastro.2017.01.042.

20. D. Cardoso, F. Teixeira-Dias, Modelling the formation of explosively formed projectiles $(E F P)$, International Journal of Impact Engineering, vol. 93, pp. 116-127 (2016). DOI: 10.1016/j.ijimpeng.2016.02.014

21. J. Wu, J. Liu, Y. Du, Experimental and numerical study on the flight and penetration properties of explosively-formed projectile, International Journal of Impact Engineering, vol. 34, iss. 7, pp. 1147-1162 (2007).

22. S. Rolc, J. Buchar, Z. Akstein, Computer simulation of explosively formed projectiles (EFP), Proc. of the 23th Int. Symp. on Ballistics. Tarragona, Madrid, Spain, 16-20 April 2007, Universidad Politécnica de Madrid, International Ballistics Committee, Madrid, pp. 185-192 (2007) 